\title{
The moderating effect of collective efficacy on the relationship between environmental values and ecological behaviors
}

\author{
E. Cuadrado ${ }^{1,2}$ (D) L. H. Macias-Zambrano ${ }^{3}$ A. J. Carpio ${ }^{4,7} \cdot$ C. Tabernero ${ }^{5,6}$ (D)
}

Received: 3 June 2020 / Accepted: 21 June 2021 / Published online: 4 July 2021

(C) The Author(s) 2021, corrected publication 2021

\begin{abstract}
Sustainability implies improvements in responsible behaviors such as recycling and energy saving. Yet, ecological behaviors cannot be improved only by attending to personal variables; focus must also be put on the collective variables. The main aim of this research was to analyze how individual variables (environmental values) and collective variables (collective efficacy for ecological behavior) interact to explain recycling (Study 1; 502 students of Spanish universities) and energy-saving behaviors (Study 2; 544 students of Ecuadorian universities). Participants completed an online questionnaire that reflected all the studied variables. Ecological behaviors were collected through frequency scales. The results of the moderated analyses performed with Process for SPSS confirmed the moderating effect of collective efficacy in the relationship that both preservation and appreciation established with recycling and energy-saving behavior alike. This moderating effect was also confirmed in the relationship that utilization developed with recycling, but not with energy saving. Thus, collective efficacy directly influences pro-environmental behavior, but also interacts with the personal values of individuals. Consequently, the results indicate the need to encourage collective efficacy for ecological behaviors of individuals, groups, collectives, and communities.
\end{abstract}

Keywords Recycling · Energy saving $\cdot$ Preservation value $\cdot$ Utilization value $\cdot$ Appreciation of nature value $\cdot$ Collective efficacy

E. Cuadrado

esther.cuadrado@uco.es

1 Maimonides Biomedical Research Institute of Cordoba (IMIBIC), Córdoba, Spain

2 Faculty of Education Sciences, University of Córdoba, Avenida San Alberto Magno S/N, 14071 Córdoba, Spain

3 Lay University Eloy Alfaro of Manabi, Manta, Ecuador

4 SaBIO group, Institute for Research in Hunting Resources IREC (CSIC-JCCM-UCLM), Ciudad Real, Spain

5 University of Salamanca, Salamanca, Spain

6 Neurosciences Institute of Castilla Y Leon (INCyL), Salamanca, Spain

7 Department of Zoology, University of Córdoba, Córdoba, Spain 


\section{Introduction}

Whether consciously or unconsciously, the normal functioning of industrialized societies produces environmental changes (Ollinaho, 2016; Rudel et al., 2011). Population, economics, capitalism, and industrial growth are all related to perhaps the greatest challenges faced by humanity today: growing global resource demands and exploitation, environmental degradation, and climate change (Everard et al., 2016; Nasrollahi et al., 2018). Encouraging pro-environmental and ecological behaviors in individuals and society is critical for the planet's sustainability, especially in societies that use natural resources unsustainably until they are despoiled (Jia et al., 2019; Milfont \& Duckitt, 2004). To this end, numerous studies have paid special attention to the personal variables that may affect how individuals behave with regard to the environment (Corraliza \& Berenguer, 2000; Fritsche et al., 2018). One of the most commonly studied variables is environmental values, referring to individuals' priorities and guiding principles regarding the use of nature and how they view the world and perceive that it might be preserved or exploited, thereby driving their decision making and actions related to the natural environment (Dutcher et al., 2007; Schultz et al., 2004; Tadaki et al., 2017). These values have been conceptualized as a condition to behave pro-environmentally (Kaiser et al., 2005) and have been associated with various pro-environmental behaviors (Corraliza \& Berenguer, 2000; Milfont et al., 2010). However, although pro-environmental behavior has been studied primarily as an individual decision-making process, especially pertaining to the personal variables that drive it (Fritsche et al., 2018), personal behaviors are affected not only by individual variables (Ferguson \& Branscombe, 2010; Fritsche et al., 2018; Jugert et al., 2016). Social psychology has demonstrated that external conditions - and in particular the group, community, or collectivity to which individuals belong — strongly influence people's behavior (Reicher et al., 2010). What the group does, or what one perceives that the group does, has the power to influence us and change our way of behaving. Therefore, psychologists must pay attention to the collective variables that can affect ecological behavior (Fritsche et al., 2018). In this sense, authors have argued that altering behaviors toward a sustainable society necessitates attention not only to individual variables but also to the collective practices that may facilitate (or, in contrast, impede) pro-environmental actions (Bamberg et al., 2015; Peattie \& Peattie, 2009; Shove, 2010).

Consequently, the aim of this investigation is to analyze how individual and collective variables interact to explain ecological behavior. At the individual level, environmental values are considered, which are defined by Corral-Verdugo et al., (2020, p. 7274) as "principles that help people to develop a more sustainable relationship with the environment." At the group or community level, collective efficacy is considered, which is defined by sBandura (2000) as a group's shared belief in its conjoint capabilities to successful undertake a specific behavior.

\subsection{Environmental values and ecological behavior}

Bogner and Wiseman (2006) have reported two Major Environmental Values (2-MEV): preservation, which reflects a biocentric perspective regarding the need to care, protect, and preserve the natural environment, and utilization, which reflects an anthropocentric view of the need to exploit and alter nature, understood as a source of resources available for human consumption (Wiseman \& Bogner, 2003). According to the 2-MEV conception (Bogner \& Wiseman, 2006), the two dimensions are not opposed; that is, individuals 
can simultaneously perceive that natural resources must be preserved and used by humans (Bogner, 2018; Milfont \& Duckitt, 2004). Bogner (2018) has recently added a new dimension to the 2-MEV-appreciation of nature-reflecting a biocentric view of the benefit and enjoyable use of nature.

Numerous studies have assessed the relationship between environmental values and proenvironmental behaviors, but relatively few studies have analyzed the impact of the preservation and utilization values as orthogonal dimensions, as well as of the appreciation of nature on environmental and ecological behaviors (Bogner, 2018). In the various studies exploring the relationship between the two orthogonal dimensions of the environmental values cited above and environmental behaviors in recent years, preservation has been consistently related to pro-environmental behavior, but not utilization. In this sense, Milfont and Duckitt (2004) and Boeve-de Pauw and Van Petegem (2013b) found that preservation, but not utilization, predicted environmental behavior. Nevertheless, Binngießer and Randler (2015) found both preservation and utilization to be related to pro-animal attitudes (attitudes toward farm and companion animals), a construct they found to be closely related to pro-environmental attitudes. Along the same lines, Boeve-de Pauw and Van Petegem (2013b) noted that preservation consistently predicted pro-environmental behavior in different cultures, while utilization predicted it in some cultures but not in others. Moreover, to date, few studies have explored the relationship of appreciation of nature with pro-environmental and ecological behaviors.

Nevertheless, Kibbe et al. (2014) discovered that exploitative utilization and appreciative utilization predicted preservation negatively and positively, respectively, and concluded that individuals who appreciate nature will preserve the environment. Moreover, Kaiser et al. (2014) recognized that the more individuals appreciate nature, the more positive their attitudes are toward the protection of environment. It has also been seen that people who engage in appreciative outdoor recreation behave in more pro-environmental ways (Nord et al., 1998). Moreover, individuals with higher levels of appreciation of nature engage in more gardening (Clayton, 2007) and general ecological behaviors (Roczen et al., 2014).

In accordance with the literature cited above, and owing to inconsistencies between the different studies, we will explore the relationship between utilization and pro-environmental behavior. Thus, the first research question of this study is this: Does a significant relationship exist between utilization value and pro-environmental behavior?

Also, in congruence with the literature review, we therefore hypothesized that both preservation and appreciation values would predict pro-environmental behaviors.

Hypothesis 1 Individuals with higher levels of (a) preservation and (b) appreciation values about nature will behave in a more pro-environmental way.

We will now focus on collective efficacy for ecological behavior as a collective variable determinant of pro-environmental behavior.

\subsection{Collective efficacy and ecological behavior}

As Bandura (2006) has explained, individuals are influenced by the beliefs of those around them, that is, their community and groups. Based on the self-efficacy and collective efficacy concepts formulated by Bandura (2006, 2010), collective efficacy for ecological behavior can be understood as people's shared perceptions about the ability of their group 
or collectivity to undertake ecological behaviors successfully. This core belief will inevitably implicate individuals' ecological behavior, because it affects motivation and performance (Bandura, 2006, 2010). In accordance with Bandura (2006, 2010), those who do not believe that they or their group can behave pro-environmentally will probably not try to act in this manner or will stop as soon as they encounter any difficulty. Therefore, collective efficacy may predict pro-environmental behavior (Chen, 2015; Jugert et al., 2016; Tabernero \& Hernández, 2011a): the more individuals and groups believe in the capacity of the community to behave pro-environmentally, the more they will engage in ecological behaviors. When individuals perceive their group as having the capacity to behave proenvironmentally, they gain an individual sense of control, their self-efficacy increases, and they act individually in group terms, that is, in a more pro-environmental way (Jugert et al., 2016).

However, collective efficacy has been perceived not only as a direct predictor of behaviors, but also as a consistent moderator of the relationship between personal variables and behaviors (Cuadrado \& Tabernero, 2015; Tabernero et al., 2015; Tasa et al., 2011). Tabernero et al. (2015) have identified interaction effects between different variables and collective efficacy when predicting pro-environmental behavior. They demonstrated in a multilevel study that the relationship between different individual variables and recycling was moderated by collective efficacy in communities: individuals with strong efficacy beliefs and a high satisfaction with service quality recycle more when they belong to a community with greater collective efficacy.

Therefore, it is possible to conceive that collective efficacy for ecological behavior will moderate the relationship established between environmental values and pro-environmental behavior, as it will enhance the positive impact of preservation and appreciation on proenvironmental behavior and reduce the possible negative impact of utilization on pro-environmental behavior.

According to the literature described above, the second research question of this study is this: If the utilization value establishes a relationship with pro-environmental behavior, will collective efficacy moderate this relationship by reducing the potential negative impact of utilization on pro-environmental behavior?

Moreover, we expect that collective efficacy will predict pro-environmental behavior and interact with preservation and appreciation to explain pro-environmental behavior, by moderating the relationship established between environmental values (preservation and appreciation) and pro-environmental behavior.

Hypothesis 2 When holding high collective efficacy for ecological behaviors, individuals with high levels of (a) preservation and (b) appreciation will behave in a more proenvironmental way than individuals with lower levels of collective efficacy.

\subsection{Sociodemographic variables}

Sociodemographic variables (Scannell \& Gifford, 2013; Tabernero et al., 2015), and specifically place of residence, have also constituted the focus of interest in pro-environmental studies. Studies that explored the role played by place of residence have revealed inconsistencies, with some finding that people in rural areas, who may be expected to be more in touch with nature, report greater pro-environmental behaviors (Berenguer et al., 2005; Gifford \& Nilsson, 2014), whereas others have found that people living in cities with higher numbers of inhabitants are more pro-environmental (Gifford \& Nilsson, 2014; Tabernero 


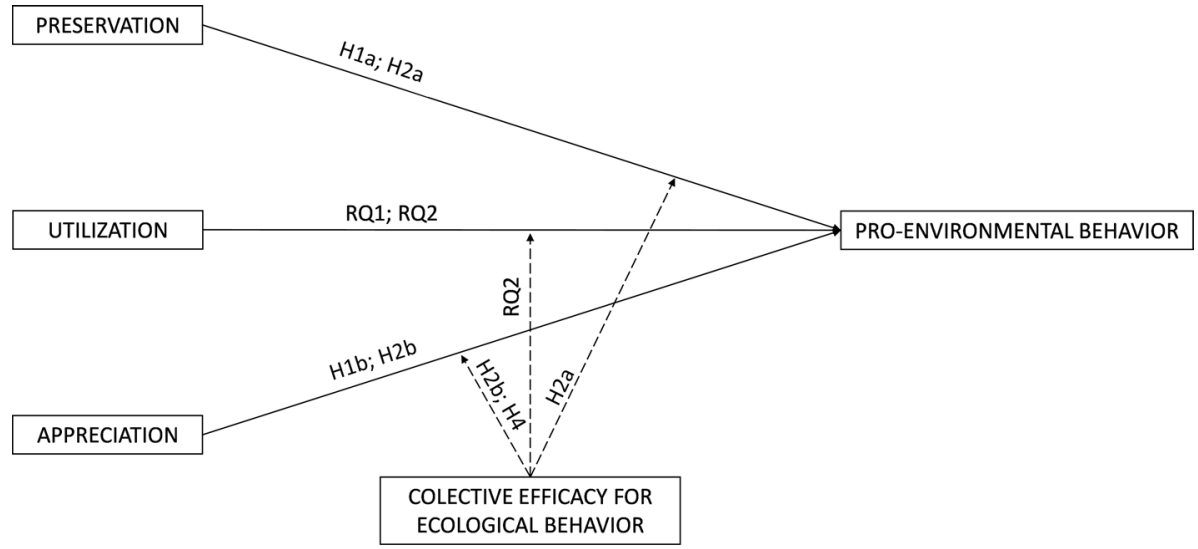

Fig. 1 Schematic representation of the relationship between hypotheses (H1a; H1b; H2a; H2b and H4) and research questions (RQ1 and RQ2). Note $\mathrm{H}=$ hypothesis; $\mathrm{RQ}=$ research question

et al., 2015), perhaps owing to the greater possibilities they are afforded to act in such ways (greater accessibility to containers, greater exposure to campaigns, etc.).

Therefore, we propose the following new hypotheses:

Hypothesis 3 Place of residence will predict pro-environmental behavior, this being greater among urban people than rural people.

Hypothesis 4 The interactions hypothesized on hypothesis 2 will remain in the presence of place of residence as covariate. It means that the moderating role of collective efficacy in the relationship established between (a) preservation and pro-environmental behavior and (b) appreciation and pro-environmental behavior will remain in the presence of place of residence as covariate.

Moreover, the third research question is whether the moderating role of collective efficacy in the relationship established between utilization and pro-environmental behavior will remain in the presence of place of residence as covariate.

In brief, we propose the relationships shown in Fig. 1.

\subsection{Individual ecological behaviors: recycling and energy saving}

Individuals are generating more and more household waste in our consumerist societies. Moreover, the waste produced is of all types: food and water waste, waste from electrical and electronic equipment, packaging waste, and so forth. Consequently, sustainability implies responsible waste management from individuals (United Nations Environment Programme, 2011), including recycling behaviors to reduce pollution and the depletion of natural resources, while saving more energy (Cui \& Zhang, 2008; Echegaray \& Hansstein, 2017; King et al., 2006; Zeng et al., 2015). As such, studies regarding how best to increase recycling behaviors seem to be growing in relevance. To this end, we will respond to the hypotheses provided by exploring them in relation to recycling behavior as a dependent variable with a Spanish sample. 
Moreover, climate change and the depletion of natural resources are two significant problems in our society. Today's society is associated with high levels of demand for energy not only from industries, but also individuals' homes. Indeed, the energy consumption generated at home constitutes a fairly high share of global energy consumption (Zhou $\&$ Yang, 2016). Thus, one means of reducing climate change and resource depletion is to stimulate energy-saving behaviors among individuals, both at home and at work, which renders studies about how to increase individuals' energy-saving behaviors highly relevant. Therefore, we will also respond to the research questions and hypotheses with energy saving as an ecological behavior observed, this time in an Ecuadorian sample instead.

\section{Method}

Two studies were performed, the first one in a Spanish sample, and the second one in an Ecuadorian sample. In Study1, we respond to all the research questions and to hypotheses 1 and 2, by using recycling behavior as our dependent variables.

In Study 2, we replicate the results found in Study 1, but by using another pro-environmental behavior, namely energy saving, and by considering another cultural sample, Ecuadorian individuals. Moreover, we responded not only to hypotheses 1 and 2, but also to hypotheses 3 and 4 .

This research has a cross-cultural approach, and it shares the application of the same instruments for both samples. Gálvez-Ruiz et al. (2018) justify the validity of applying instruments in the contexts of Spain and Ecuador, which, although culturally different, share the same language. The economic context is different in both countries, and this aspect could be relevant to explore if the results are maintained in those two different contexts.

\subsection{Participants}

\subsubsection{Study one}

The Spanish sample ${ }^{1}$ comprised 502 students of different vocational courses at the University of Córdoba (95\%) and the University of Salamanca (5\%) in Spain. The former is located in a city with a population of over 370,000 inhabitants; the latter is in a smaller city, containing fewer than 160,000 inhabitants. Some of the authors are originally from Spain, and they were granted permission to apply the instruments in those universities. Regarding the careers for which the participants were training, $32.7 \%$ of the participants were enrolled in teacher training for children's education, $23.5 \%$ in teacher training for elementary school, $20.5 \%$ in biology, $7.4 \%$ in psychology, $7.2 \%$ in labor relations and human

\footnotetext{
1 By computing a priori power analysis with $\mathrm{G}^{*}$ power software for $\mathrm{F}$ tests as tests family and linear multiple regression as statistical test, and by entering three as the number of tested predictors and three as the total number of predictors, while asking for an effect size of small to medium (0.05), the optimal total sample size was 348 participants, with a power of 0.95 . Moreover, when computing post-hoc power analysis with $\mathrm{G}^{*}$ power software, once more for $\mathrm{F}$ tests as tests family and linear multiple regression as statistical test, and by entering three as the number of tested predictors, three as the total number of predictors and 502 as the total sample size, the output parameter for power was 0.99 . Therefore, our sample size was sufficient.
} 
resources, $5.2 \%$ in social education, and $3.6 \%$ in sociology. Most of the respondents to the questionnaire were women $(77.5 \%)$. The average age of the sample was 21.21 years $(\mathrm{SD}=3.92,[18,49])$.

\subsubsection{Study two}

The Ecuadorian sample ${ }^{2}$ comprised 544 students at different universities in Ecuador. In this case, one of the authors is originally from Ecuador, and all the authors got access to apply the instruments in those universities. Specifically, $40.8 \%$ of the students were enrolled in the Technique University of Manabí, 30.1\% in the Laic Eloy Alfaro of Manabí University, $17.6 \%$ in the Agricultural Polytechnic Superior School of Manabí, and $11.4 \%$ in the South of Manabí State University. Students were pursuing courses in administration (29.8\%), teacher training, psychology, and pedagogy (28.7\%), environmental, forest, and agricultural engineering (27.1\%), marketing engineering (5.4\%), veterinary (3.9\%), nursing (2.6\%), and others (2.5\%). More women (62.7\%) than men completed the questionnaire. The average age of the sample was 21.23 years $(\mathrm{SD} \pm 3.95,[18,45])$. Most of the participants $(61.4 \%)$ were living in an urban area, while $38.6 \%$ were living in a rural area.

\subsection{Procedure}

This study, which was previously approved by the Research Ethical Committee of Córdoba, was correlational and transversal. The university professors disseminated a link to an online questionnaire with sociodemographic, individual, and collective variables on the website of the courses they were teaching and invited their students to participate voluntarily. Students could participate using either their computer or cellphone.

To answer the questionnaire, the participants had to first give their informed consent. For informed consent, they were advised that participation was voluntary and anonymous, and that they could withdraw whenever they wanted.

\footnotetext{
2 As in Study 1, we computed a priori power analysis for $\mathrm{F}$ tests family and linear multiple regression analysis as statistical test in $\mathrm{G}^{*}$ power software, but this time by entering three as the number of tested predictors and four as the total number of predictors (in each moderation analysis three predictors were entered to respond to our moderating hypotheses, as well as place of residence as covariate to control the effect of third variables). The results were the same as in Study 1. Moreover, when computing a priori power analysis for a one-way ANOVA analysis, entering two as the number of groups and by asking once more for an effect size of small to medium (0.18), the results for an optimal total sample size were 404 participants, with a power of 0.95 .

In addition, when computing the same post hoc power analysis for linear multiple regression analysis with G* power software as in Study 1, but by entering three as the number of tested predictors, four as the total number of predictors, and 544 as the total sample size, the output parameter for power was 0.99 . Moreover, when conducting the post hoc analysis for the one-way ANOVA statistical test by entering 544 as the total sample size, the output parameter for power was 0.99 . Therefore, our sample size was sufficient.
} 


\subsection{Measures}

\subsubsection{Sociodemographic data}

Information on age, sex, university of enrollment, and career was collected to describe the sample. For Study 2, place of residence was added to the sociodemographic variables collected.

\subsubsection{Environmental values}

Participants' environmental attitudes were measured using the Environmental Values (2-MEV) and Appreciation of Nature Scale (Bogner, 2018). This scale enabled us to assess the preservation (PRE), utilization (UTI), and appreciation of nature (APP) attitudes of participants. Preservation refers to participants' attitudes toward the conservation of the environment, utilization refers to their attitudes toward its exploitation, and appreciation refers to their attitudes toward its enjoyable use. Each of the three dimensions was composed of seven items, to which participants responded using a 5-point Likert scale, on which 1 signified "do not agree at all" and 5 "totally agree." The factorial analysis with oblique rotation using the Promax procedure and with kappa set to the default value of four revealed that the items were loaded in the three expected factors, as in the original scale. Reliabilities for the three dimensions were high for both the Spanish $(\alpha \mathrm{PRE}=0.73$; $\alpha \mathrm{UTI}=0.79 ; \alpha \mathrm{APP}=0.88)$ and the Ecuadorian $(\alpha \mathrm{PRE}=0.85 ; \alpha \mathrm{UTI}=0.78 ; \alpha \mathrm{APP}=0.94)$ samples.

\subsubsection{Perceived collective efficacy for ecological behavior}

In order to measure the extent to which individuals perceived that their group could undertake ecological behaviors, we created an ad hoc scale of eight brief items (see Appendix 1) by following Bandura's (2006) guide to constructing self-efficacy scales, and adapting and extending the self-efficacy for recycling behavior scale used by Tabernero and Hernán$\operatorname{dez}(2011 \mathrm{a}, \mathrm{b})$. The participants responded in a 5-point Likert scale in which 1 was "not at all confident" and 5 was "totally confident." Reliability was high for both the Spanish $(\alpha=0.90)$ and the Ecuadorian $(\alpha=0.96)$ samples, in accordance with the original self-efficacy for recycling behavior scale $(\alpha=0.90)$ used by Tabernero and Hernández $(2011 \mathrm{a}, \mathrm{b})$.

\subsubsection{Individual ecological behavior}

Ecological behaviors were collected through frequency scales. Two different individual ecological behaviors were studied: recycling and energy-saving behaviors.

2.3.4.1 Recycling behavior The extent to which individuals recycle was measured for Study 1 through an ad hoc self-created frequency scale comprising three short items (see Appendix 1), to which participants responded using a 5-point Likert scale, on which 1 was "never" and 5 was "always." Reliability was adequate $(\alpha=0.70)$. The mean of the three items was calculated, and higher scores of this mean indicated higher individual ecological behavior.

2.3.4.2 Energy-saving behavior The extent to which individuals carry out ecological behaviors oriented to saving energy was measured for Study 2 via an ad hoc self-created 
frequency scale of six items (see Appendix 1). The items were created using the general measure of ecological behavior (Casey and Scott, 2006), as well as the recommendations proposed by Greenpeace to achieve ecological energy-saving behaviors. Reliability was high $(\alpha=0.80)$. Participants responded to the scale through a 5-point Likert scale, where 1 was "never" and 5 was "always." The mean of the six items was calculated, and higher scores of this mean indicated higher individual ecological behavior.

2.3.4.3 Statistical analyses To check the means and standard deviations of the variables as well as the relationships between them, some descriptive correlational analyses were performed.

To confirm the moderation hypotheses, different moderation analyses were performed using model 1 of the Process for SPSS Macro (Hayes \& Preacher, 2013), with 10,000 repeated samples of bootstraps and an interval of confidence of 95\%. Model 1 of the Process for SPSS Macro calculates the conditional (or moderated) effect of an independent variable (IV) on a dependent one (DV). Environmental values (in the first moderation analysis, preservation; utilization in the second one; and appreciation in the third one) were introduced as IV. Perceived collective efficacy for ecological behavior was introduced as moderator. The environmental values that were not introduced as IV in each analysis were introduced as covariates in order to control the effects of other variables. ${ }^{3}$ Finally, individual ecological behavior (recycling behavior for Study 1 and energy-saving behavior for Study 2) was introduced as a dependent variable. Those moderation analyses were first computed without covariates, and then with the covariates cited. Moreover, for Study 2, and to test Hypotheses 3 and 4, place of residence (coded as -5.00 for individuals living in rural areas and 5.00 for individuals living in urban areas) was included as another covariate.

To confirm the hypothesis regarding the influence of place of residence in the individual ecological behavior, a one-way analysis of variance (ANOVA) was performed in Study 2, with energy-saving behavior as DV and place of residence as IV.

\section{Results}

\subsection{Preliminary analyses}

The Pearson's correlation analyses performed showed that all the variables were related as expected for both studies (see Table 1). These results are in line with the expectation for research question 1 and hypothesis 1 .

\footnotetext{
${ }^{3}$ It means, in the first moderation analysis, in which preservation was introduced as IV, both utilization and appreciation were introduced as covariates; in the second moderation analysis, in which utilization was introduced as IV, both preservation and appreciation were introduced as covariates; and in the third moderation analysis, in which appreciation was introduced as IV, preservation and utilization were introduced as covariates.
} 
Table 1 Means, standard deviation, and correlation between all the study variables for the Spanish and the Ecuadorian samples

\begin{tabular}{lllllllll}
\hline & Preservation & Utilization & Appreciation & CEfEB & ISEB & IRB & Mean & SD \\
\hline Preservation & - & $\mathbf{- . 0 9}$ & $\mathbf{4 6} * * *$ & $\mathbf{3 0} * * *$ & $\mathbf{. 3 9} * * *$ & - & $\mathbf{4 . 2 4}$ & $\mathbf{0 . 7 7}$ \\
Utilization & $-.32 * * *$ & - & $-.08 *$ & $\mathbf{. 0 2}$ & $-\mathbf{0 5}$ & - & $\mathbf{2 . 7 8}$ & $\mathbf{0 . 8 8}$ \\
Appreciation & $.31 * * *$ & $-.15 * *$ & - & $\mathbf{3 6} * * *$ & $\mathbf{. 3 4} * * *$ & - & $\mathbf{4 . 2 2}$ & $\mathbf{0 . 7 4}$ \\
CEfEB & $.18 * * *$ & .04 & $-.15 * *$ & - & $\mathbf{. 3 2} * * *$ & - & $\mathbf{3 . 8 7}$ & $\mathbf{0 . 9 4}$ \\
IRB & $.20 * * *$ & $-.09 *$ & $.20 * * *$ & $.16^{* * *}$ & - & - & - & - \\
ISEB & - & - & - & - & - & - & $\mathbf{4 . 1 6}$ & $\mathbf{0 . 7 1}$ \\
Mean & 4.24 & 2.06 & 3.53 & 3.73 & - & 3.88 & - & - \\
$S D$ & 0.60 & 0.75 & 0.80 & 0.77 & - & 0.93 & - & - \\
\hline
\end{tabular}

$* * * p<.001 ; * * p<.01$

Lower triangle, highlighted in italic: data for the Spanish sample; upper triangle, highlighted in bold: data for the Ecuadorian sample

$C E f E B$ Collective efficacy for ecological behavior; IRB individual recycling behavior; ISEB individual saving energy behavior; $S D$ standard deviation

\subsection{Moderation analyses}

For Study 1, the moderation analyses confirmed that collective efficacy for ecological behavior moderated the relationship established between environmental values and recycling behavior (Table 2), confirming hypotheses 1 and 2 and research questions1 and 2. The effect of the moderator on the environmental values-recycling behavior link can be observed in Fig. 2a.

For Study 2, as stated by the results and in accordance with Study 1, the moderated analyses confirmed that the collective efficacy for ecological behavior moderated the relationships established between environmental values (except for utilization) and energysaving behavior (Table 3), by confirming hypotheses 1 to 3 , and partially hypothesis 4 , but not research questions 1 and 2 . The effect of the moderator on the environmental values-energy-saving behavior link can be observed in Fig. 2 b.

\subsection{Differences in energy saving depending on the sociodemographic variables}

The results of the ANOVA confirmed hypothesis 3 regarding place of residence $\left(M_{\text {rural }}=4.01, \mathrm{SD}=0.80 ; M_{\text {urban }}=4.26, \mathrm{SD}=0.64 ; F(1,538)=16.069, p<0.001, \mathrm{\eta}^{2}=0.03\right.$, $\mathrm{OP}=0.98)$.

The difference in the results of Study 1 and Study 2 for each one of the hypotheses and analyses can be observed on Table 4 . 


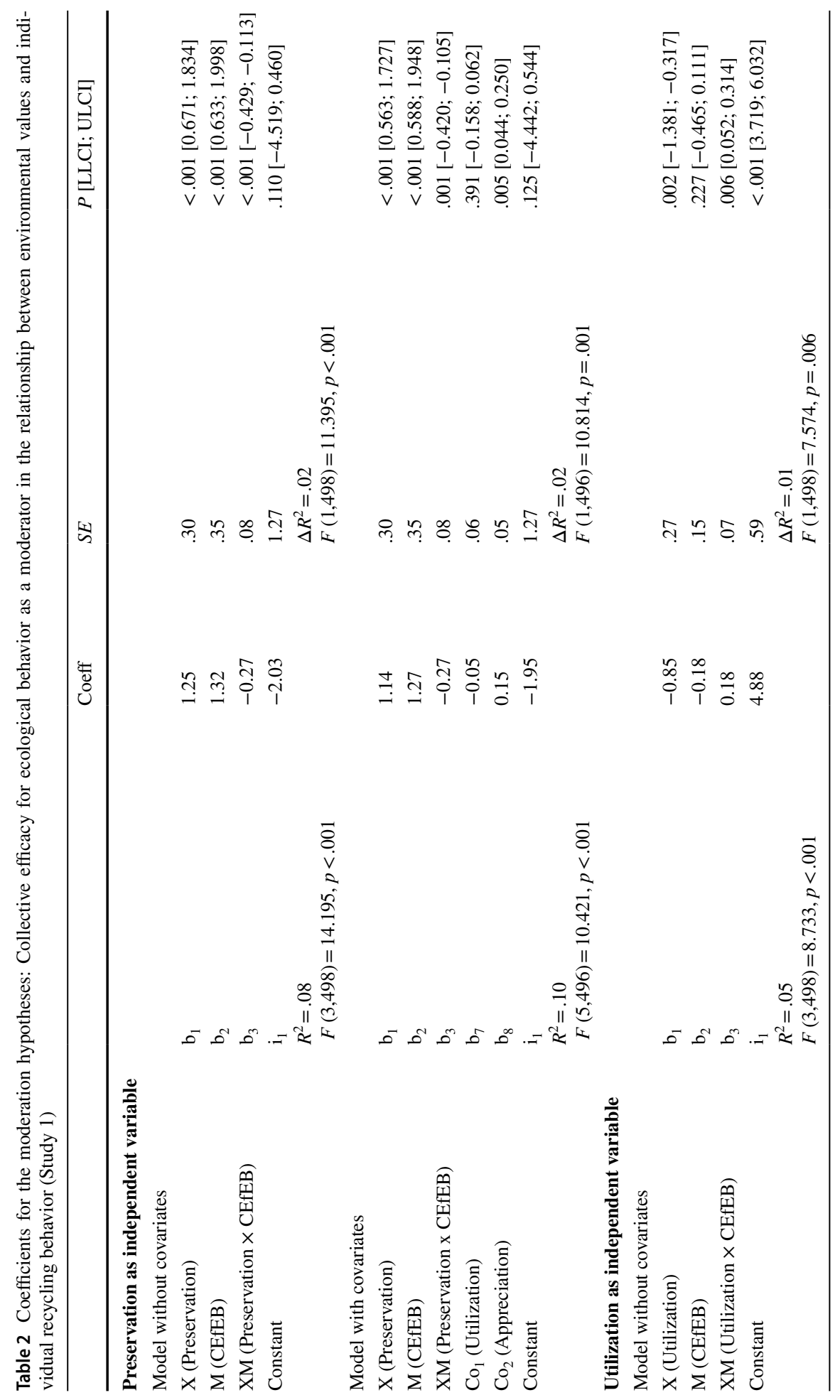




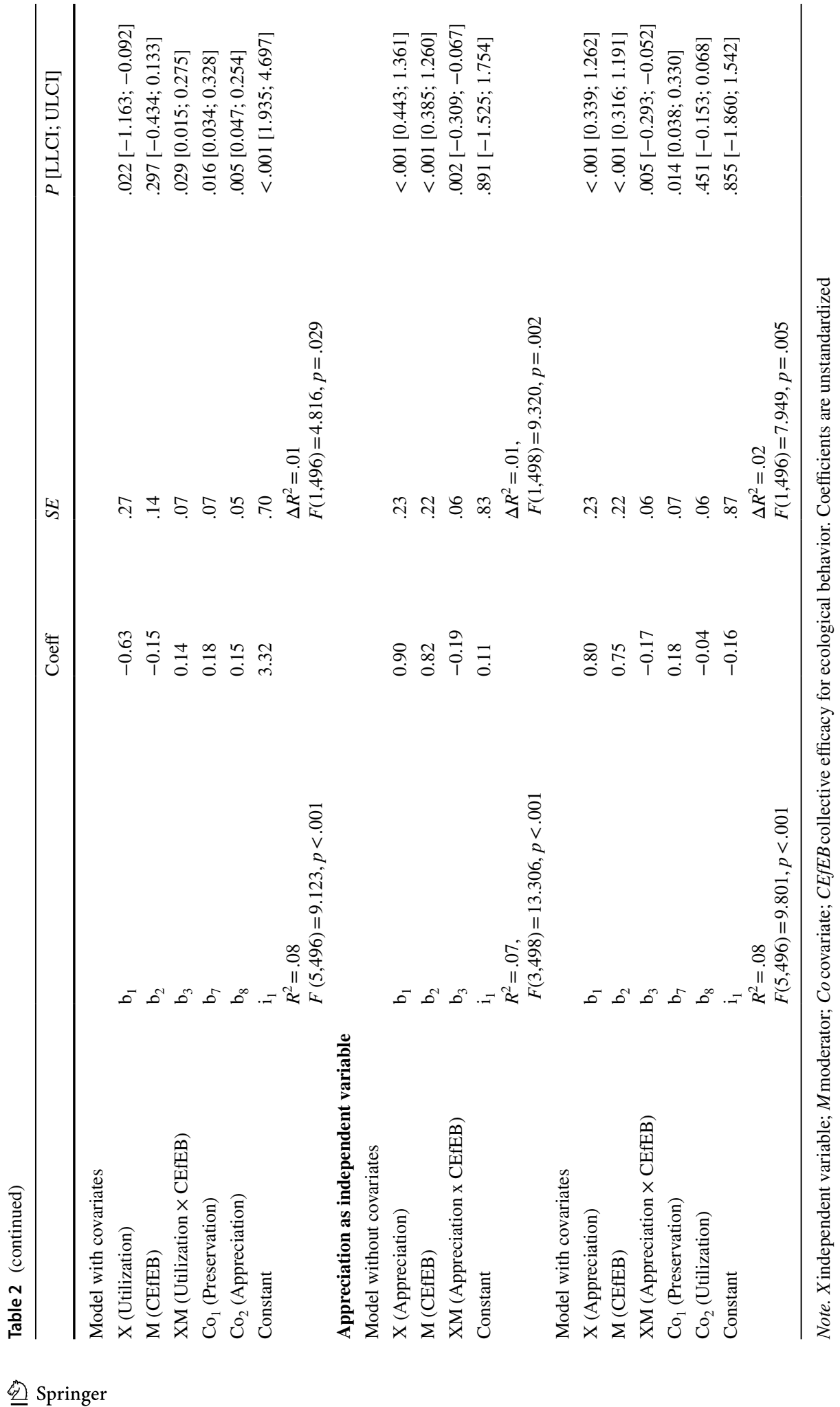




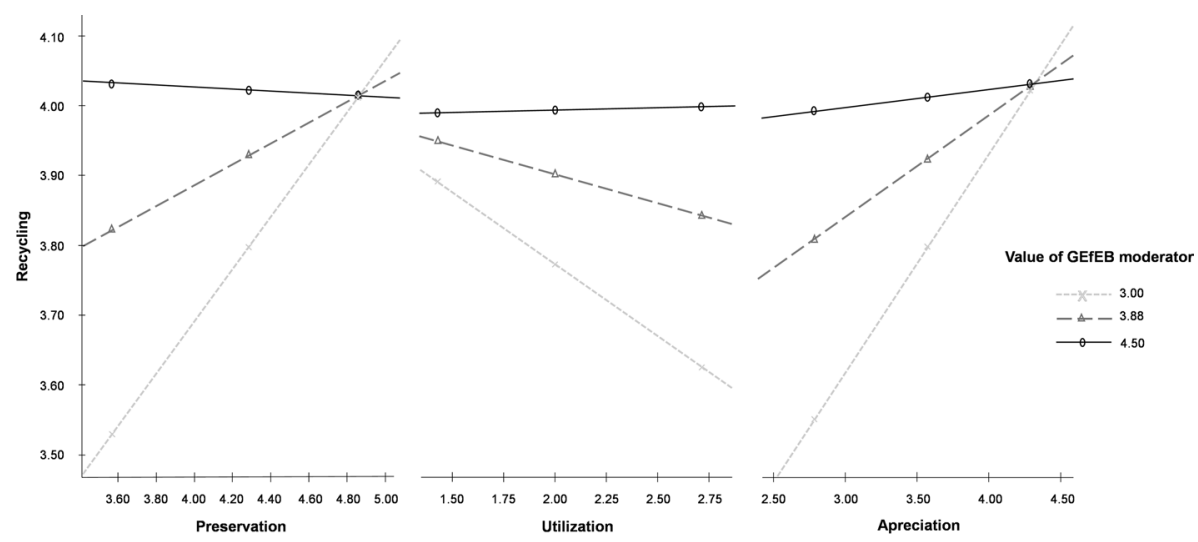

a Significant moderated effect of collective efficacy for ecological behavior in the relationship established between environmental values and recycling behavior(Study 1)

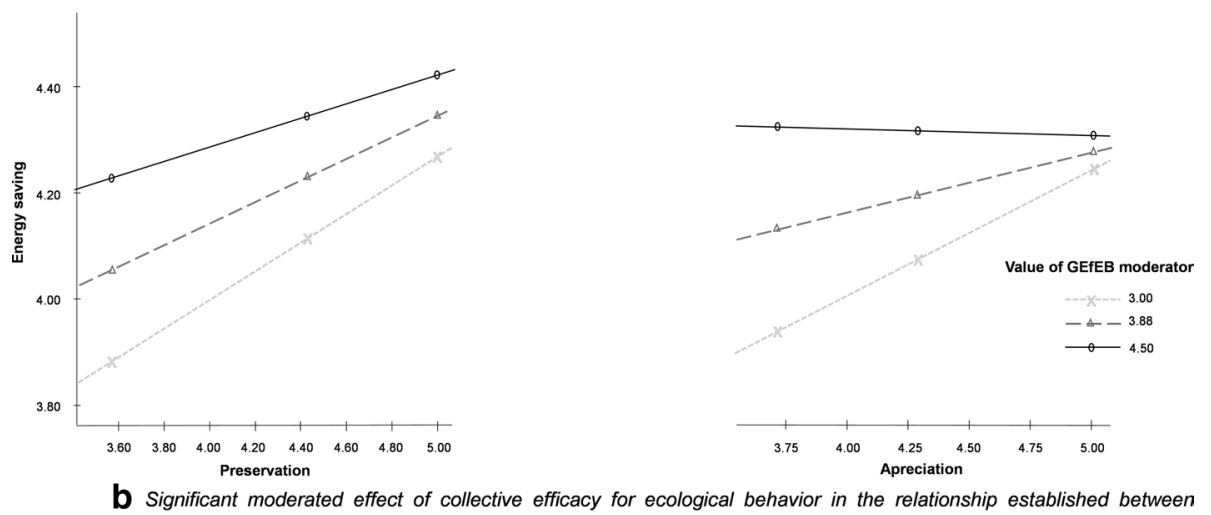
environmental values and energy-saving behavior (Study 2)

Fig. 2 Moderated effect of collective efficacy for ecological behavior in the relationship established between environmental values and pro-environmental behavior in both studies. GEfEB = Collective efficacy for ecological behavior

\section{Discussion}

\subsection{Study one}

In accordance with previous literature (Binngießer \& Randler, 2015; Kaiser et al., 2014; Kibbe et al., 2014; Mancha \& Yoder, 2015; Roczen et al., 2014), the results of Study 1 have shown that regarding the personal variable, the three environmental values explored were related to recycling. Therefore, it has been shown that the more individuals appreciate and enjoy the use of nature, and the more they value it as an item that must be preserved and protected, then the more they recycle. In contrast, the more they think that nature must be exploited by humans, the less they report recycling.

More interestingly, the distinctive contribution of this research is its confirmation that personal and collective variables interact to explain pro-environmental behavior, as other authors have claimed (Bamberg et al., 2015; Fritsche et al., 2018; Jugert et al., 2016; Tabernero et al., 


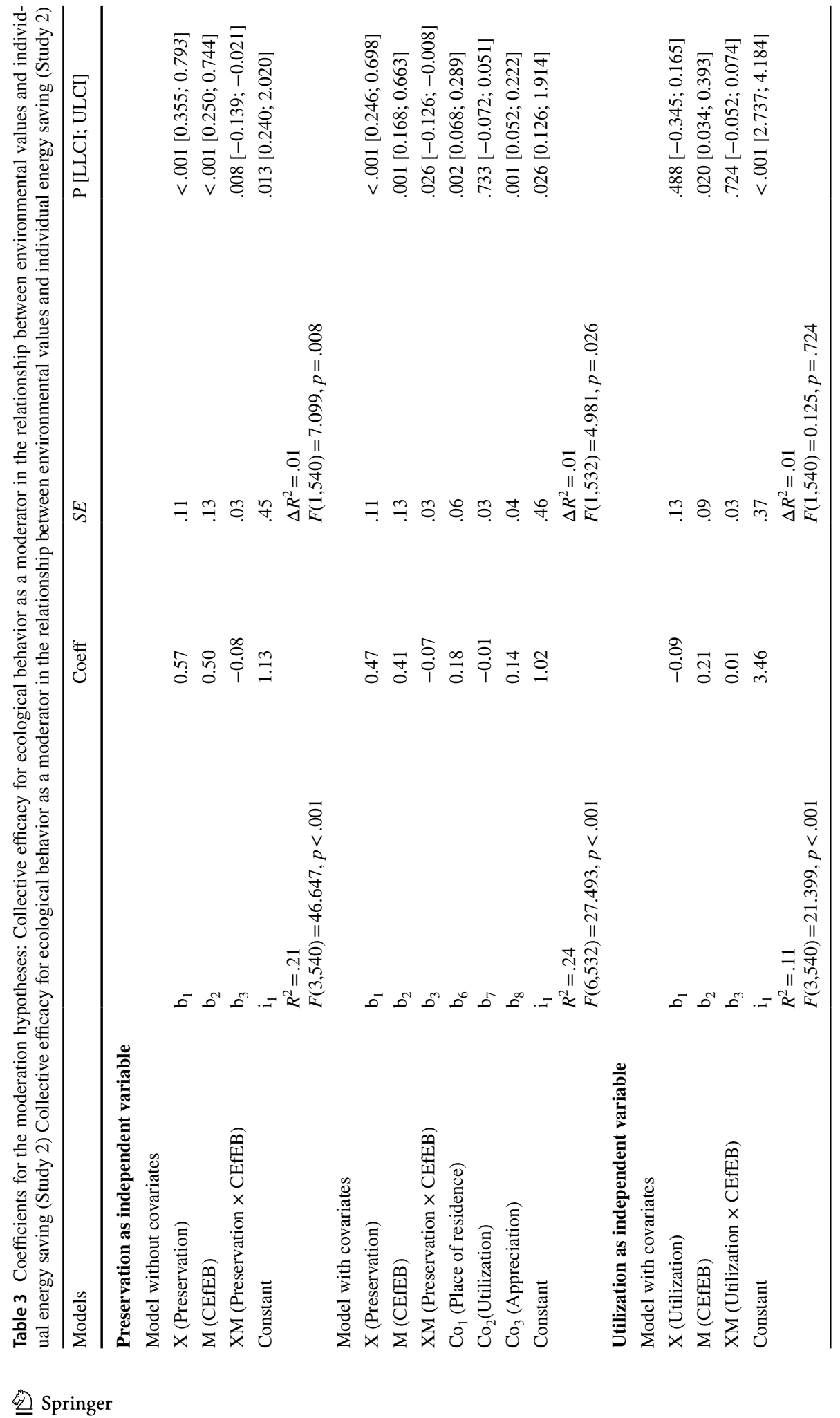




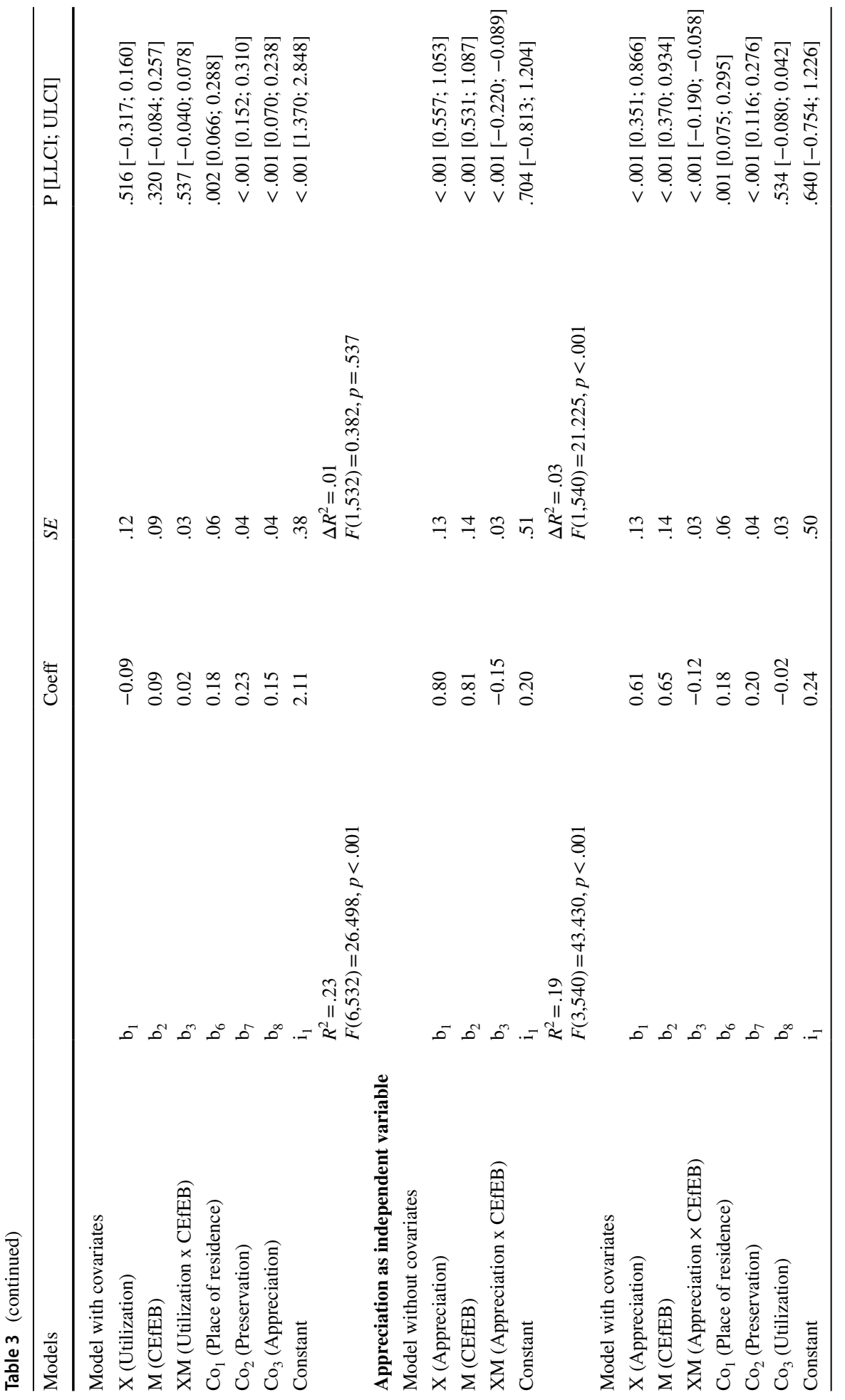




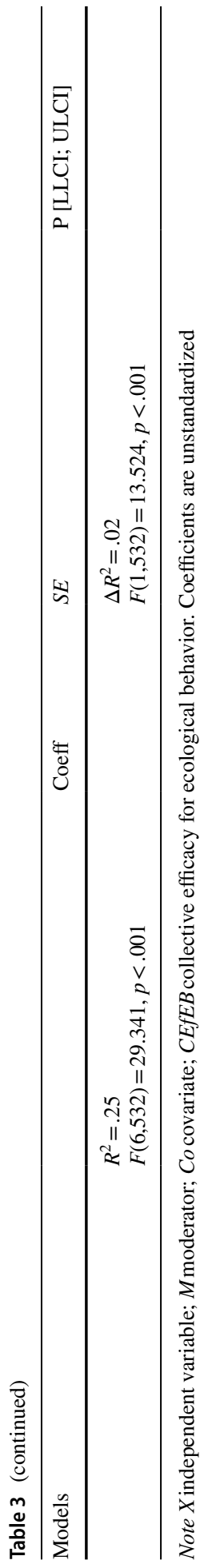

Springer 


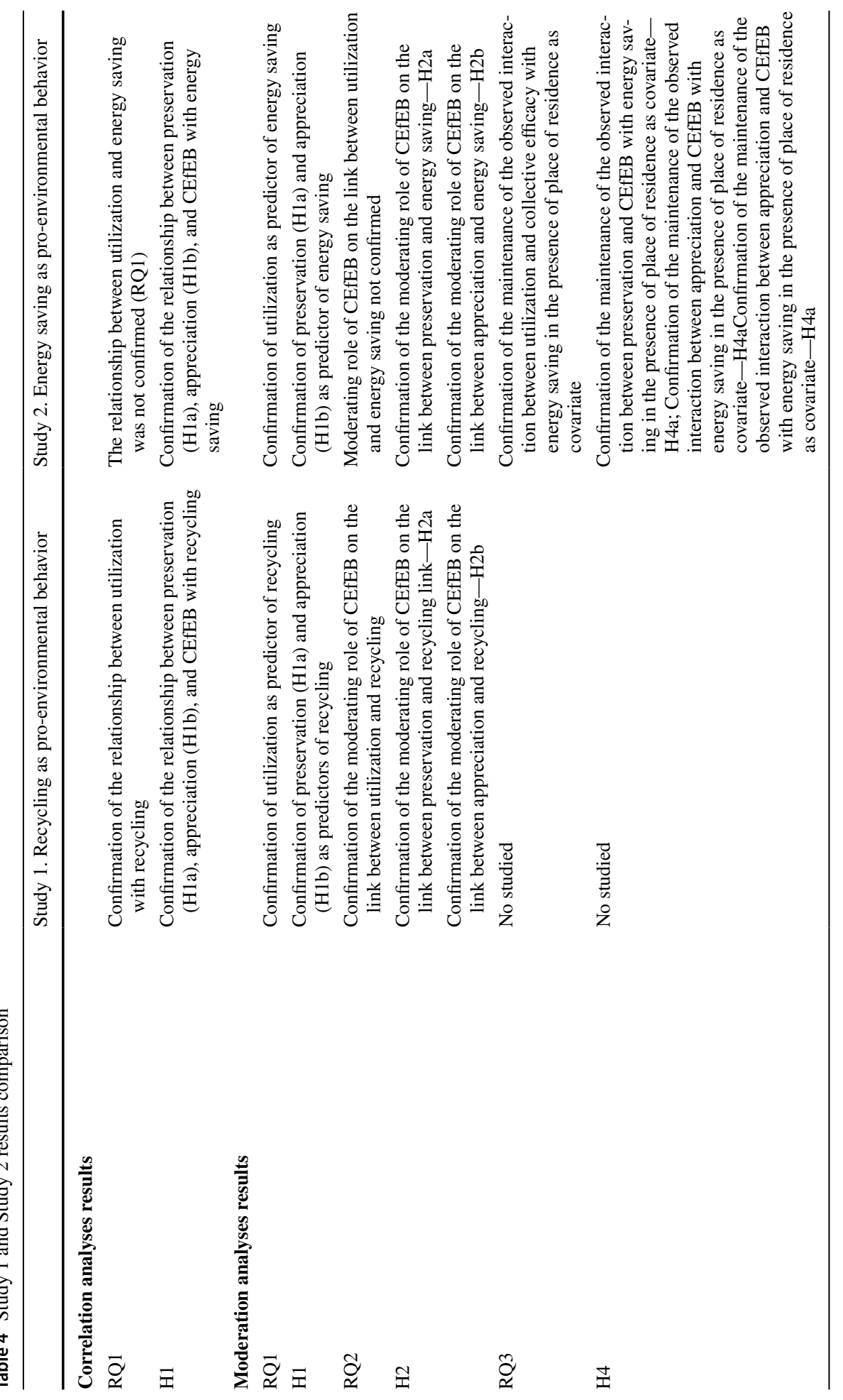




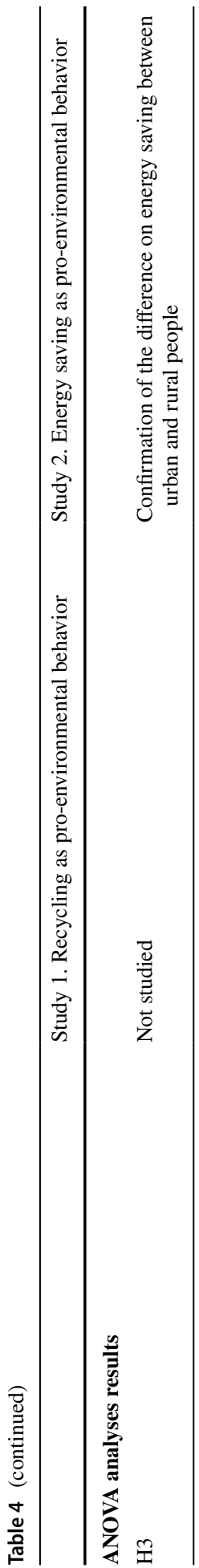

Springer 
2015); the novelty of this study is that the specific interaction explored between environmental values and collective efficacy in predicting pro-environmental behavior has not been studied in previous researches. It means, interactions between collective and individual variables have been found before, but the interaction that we have explored in this research has not been studied previously. In this sense, in Study 1, collective efficacy for ecological behavior moderated the relationships that environmental values established with pro-environmental behavior. Indeed, the results have shown that the lower the values for preservation and appreciation of nature, the greater the necessity of collective efficacy beliefs for individuals to exhibit high levels of recycling behavior; moreover, when preservation and appreciation of nature are high, levels of collective efficacy beliefs are not relevant to predict recycling behavior. In contrast, the higher the utilization value is, the more necessary collective efficacy beliefs are for individuals to present high levels of recycling behavior, while when utilization levels are low, there is no difference in the recycling behavior levels between individuals with high and low collective efficacy levels (see Fig. 2). These results indicate the pertinence of promoting collective efficacy for ecological behaviors, especially in individuals with low levels of preservation and appreciation values, or with high levels of utilization values. In this sense, the critical perspective on environmental education could be highly relevant. By using participatory collaborative activities oriented to increase the perception of the importance of maintaining biodiversity and preserving nature, typical of the critical environmental education approaches (Stevenson et al., 2017), perceived collective efficacy for ecological behaviors will be inevitably enhanced, and in turn pro-environmental behaviors displayed by individuals and societies.

\subsection{Study two}

The results of Study 2 supported almost all the results found in Study 1, as well as almost all the new hypotheses introduced. As in Study 1, and in agreement with previous studies that have found that collective and individual variables interact to explain individual behaviors, and specifically pro-environmental behavior (Cuadrado \& Tabernero, 2015; Fritsche et al., 2018; Jugert et al., 2016; Tabernero et al., 2015), the moderating effect of the collective efficacy beliefs on the relationships that both preservation and appreciation of nature established with pro-environmental behavior was confirmed. Moreover, this interaction remained in the presence of place of residence as covariate, revealing a significant impact of place of residence on pro-environmental behavior. As in Study 1, collective efficacy for ecological behavior buffered the negative impact of low preservation and low appreciation of nature on pro-environmental behavior. Nevertheless, the moderating effect hypothesized in the relationship between utilization and pro-environmental behavior was not confirmed.

In addition, individuals living in urban areas reported greater energy-saving behavior than people living in rural areas, highlighting the importance of policies oriented specifically toward rural areas. These results are in agreement with previous studies (Gifford \& Nilsson, 2014; Tabernero et al., 2015).

\section{General discussion}

Encouraging pro-environmental behaviors in individuals is necessary for the preservation and sustainability of the planet. The actions and behaviors often included in pro-environmental behaviors are always directed toward common objectives, such as preservation and/ or environmental conservation, and the resolution of environmental problems (Liu \& Chen, 
2019). The previous does not mean carrying out an individualistic education based solely on the correction of actions already performed. We cannot rely only on the sum of individual actions and expect an impact on society-on the contrary, we need to understand the complexity of environmental and social interactions and the participation of all individuals as a whole, in order to expect a social impact (de Albuquerque et al., 2015). Both recycling and energy saving are behaviors that can be undertaken by individuals at home or at work, and that have an impact on different environmental problems, including climate change, pollution, and the depletion of natural resources (Cui \& Zhang, 2008; Echegaray \& Hansstein, 2017; King et al., 2006; United Nations Environment Programme, 2011; Zeng et al., 2015). Consequently, the study of how to increase these behaviors seems to be highly relevant to advance from individual changes to community changes to bring about a new reality at the social level.

The best way to stimulate pro-environmental behavior is probably not to limit the focus to related individual variables, but rather to emphasize the collective variables that can affect them (Bamberg et al., 2015; Fritsche et al., 2018; Jugert et al., 2016; Peattie \& Peattie, 2009; Shove, 2010; Tabernero et al., 2015). Given that individuals are social by nature, they are highly influenced by the group and collectivity around them (Bandura, 2006; Ferguson \& Branscombe, 2010; Fritsche et al., 2018; Jugert et al., 2016). In this regard, the extent to which individuals perceive that their group can behave effectively in an ecological way may influence their pro-environmental behavior, as well as the extent to which their environmental values are capable of producing such pro-environmental behaviors (Chen, 2015; Jugert et al., 2016; Tabernero \& Hernández, 2011b; Tabernero et al., 2015). The results of these two studies have partially supported this hypothesis. In accordance with previous literature (Boeve-de Pauw \& Van Petegem, 2013a; Kaiser et al., 2014; Kibbe et al., 2014; Mancha \& Yoder, 2015; Roczen et al., 2014), Studies 1 and 2 have shown that the more individuals believe that nature must be preserved and protected, and the more individuals appreciate and enjoy its use, the more they report acting pro-environmentally for both pro-environmental behaviors explored (recycling and energy saving). Moreover, both studies have shown that collective efficacy for ecological behavior moderated these relationships, supporting the results attained by Tabernero et al. (2015), in which collective efficacy acts as a moderator in relationships established between other personal variables and waste management. In our two studies, the results have demonstrated that individuals with low values for preservation and appreciation of nature require high collective efficacy beliefs to endorse strong pro-environmental behaviors. These results indicate the importance of promoting high levels of belief in collective efficacy for ecological behavior, especially among those with low levels of preservation and appreciation values. Encouraging ecological behavior can be achieved via critical environmental education, through an integral approach of social, economic, and environmental dimensions (de Albuquerque et al., 2015), and by involving individuals in collective activities and approaches, typical in critical environmental education (Stevenson et al., 2017), in which they must construct collectively and through critical thinking their own though and perceptions about the importance of preserving biodiversity and nature as a whole. This can lead to a more cooperative and ecocentric society, which could favor the development of collective efficacy and thus encourage ecological behavior at both individual and societal levels.

Regarding utilization, in the same way that inconsistencies appear in the results of different studies in the scientific literature- the relationship between utilization and pro-environmental behavior not always being observed (Binngießer \& Randler, 2015; Boeve-de Pauw \& Van Petegem, 2013a; Milfont \& Duckitt, 2004)—our results have revealed inconsistencies between the two studies. The more individuals exhibited an anthropocentric 
perspective regarding the use of nature (i.e., by thinking that individuals dominate and can exploit and alter nature as they want), the less they reported recycling behaviors, while no relationship was confirmed between utilization values and energy-saving behaviors. Moreover, collective efficacy for ecological behavior moderated the relationship established between utilization and recycling (i.e., by reducing the negative impact of utilization on recycling), yet no interaction effect was found between utilization and collective efficacy in predicting energy saving. The fact that no relationship was identified between utilization and energy saving when a negative correlation might be expected may be due to the fact that energy saving can be adopted by individuals not to preserve nature, but rather in a more egoistic way. In this sense, utilization situates the individual as the main beneficiary in the use of natural resources (Schumm \& Bogner, 2016). This is because saving energy is a means of saving money as well, and so it is plausible that this latter motive influences energy-saving behavior and operates as a covariate or moderator, affecting the possible negative relationship between utilization and energy saving. This finding is therefore congruent with the notion that people with strong egoistic values and motivation will behave pro-environmentally when they perceive that the benefits outweigh the costs (de Groot \& Steg, 2008, 2009). For example, some individuals who think that nature must be exploited for human gain may save energy in order to save money (an egoistic motive), while others who agree that resources should be exploited and who moreover do not perceive that the benefits of saving energy outweigh the personal costs involved, may have no interest in preserving nature and hence may not save energy. In line with this idea, Brandsma and Blasch (2019) have found that when individuals hold egoistic values, they are less willing to save energy, except when doing so gives them a monetary benefit. Future studies may place special attention on the plausible moderation effect of egoistic motives in the relationship established between utilization and energy saving. It is important to note that this moderating effect may help explain the inconsistencies found in the studies regarding the relationship established between utilization and pro-environmental behavior. In this sense, it can be considered that several countries have endorsed payments for environmental services (Gómez-Baggethun et al., 2010; Tacconi, 2012) and that natural ecosystems can provide economic benefits - that is, what is called ecological services (McCauley, 2006). This perspective is congruent with the view of a sort of egoistic perspective, by safeguarding nature for self-benefit. Nonetheless, this economic view of the natural world and the mechanisms for conservation that are based on an economic perspective are probably not the most relevant to cope with the actual relevant ecological problems, and most authors argue that our efforts have to be reoriented to encourage connection and love for the natural world (McCauley, 2006). In this sense, a critical environmental education approach, oriented to help individuals and groups to construct moral arguments for biodiversity conservation not only based on human interest, but also on ecocentric values, seems to be highly relevant. Environmental education should be oriented to a collaborative construction of the conviction that nature and biodiversity are intrinsically of interest and have to be valued beyond their possible interest as an element at the service of individuals (Kopnina, 2020; Taylor et al., 2020). On the other hand, it is necessary to emphasize that although individuals depend on natural resources and common natural goods for their survival, the use they make of nature is not only destructive, but also many individuals make a sustainable use of them, independently if they do so for egoistic or ecocentric motives.

No egoistic motives can be perceived in terms of household recycling, as no economic benefit is obtained in either Spain or Ecuador for doing so, and thus the relationship between utilization and recycling remains. Preservation reveals selfless preservation and protection preferences toward the natural environment (Schumm \& 
Bogner, 2016). Therefore, our results confirmed that the more individuals believe that nature must be exploited by humans, the less they recycle, especially where they do not believe that their group is able to effectively behave in an ecological way. In contrast, high levels of collective efficacy for ecological behavior had the power to eliminate the negative impact of high utilization values on recycling: when individuals possess strong collective efficacy beliefs, those with high utilization values recycle to the same extent as those with low utilization values. Again, the promotion of collective efficacy beliefs seems to be relevant to stimulate pro-environmental behavior in individuals, especially among those with high utilization values. In this sense, again, critical environmental education may be highly relevant; this type of educational perspective, based on sharing collaboratively activities and critical approaches on learning, could increment not only more ecocentric values on individuals and groups, but also the necessary collective efficacy beliefs about ecological behavior, that could in turn increment pro-environmental behavior at the individual and collective level.

\section{Limitations and future research}

The major limitation of both studies is related to the samples, which comprise mostly female university students. At this stage, it should be considered that using homogeneous samples helps to reduce extreme variations in responses (Meisenberg \& Williams, 2008). It should be mentioned that the sample taken is narrow in both cases and may not fully represent the local context. Nonetheless, it is relevant to note that our student sample is composed of students of very different areas, showing in this sense some heterogeneity. Moreover, students may not differ substantially in their manner of perceiving the natural environment compared to the general population. Future studies may replicate the results of these studies in a more heterogeneous sample.

It may be relevant to note that the results have shown a significant predictive role of place of residence on energy saving, with people who live in urban areas reporting more pro-environmental behaviors, in accordance with previous studies (Gifford \& Nilsson, 2014; Tabernero et al., 2015). These differences demonstrate the need for heterogeneous samples in future investigations on pro-environmental behaviors to highlight these relationships. Moreover, as we explained earlier, the inconsistencies found in the relationship established between utilization and both pro-environmental behaviors explored might be analyzed in the future by placing the focus of attention on the plausible moderator role of egoistic motives in such relations. In this sense, comparison between countries in which an economic prize for recycling is given and those in which it is not may prove interesting, as well as experimental studies in which the economic prize gain is manipulated to observe its effects on the relationship between utilization and recycling behavior. In Ecuador, regarding recycling, the Ecuadorian Constitution derives the competence in the Decentralized Autonomous Governments (Seventh Section, Art. 415); however, there are no records of incentives for recycling aimed at individuals, but rather at companies (Burneo et al., 2020). On the other hand, in Spain, Law 11/97 of April 24, about packaging and packaging waste, and Royal 
Decree 252/2006, of March 3 regulate aspects that have to do with recycling but do not include economic incentives aimed at individuals, in the same way of the Ecuadorian regulation.

\section{Conclusions}

As concern about an increasingly degraded environment escalates in our society, the importance of and interest in pro-environmental behaviors has also risen. Although focus was initially placed on personal variables related to individual pro-environmental behavior, investigations are now exploring collective variables as well. Being social animals, individuals are inevitably influenced by the behavior of the collective. In this study, we have shown that not only does perceived collective efficacy have a direct impact on individual pro-environmental behaviors, but it also interacts with environmental values to explain individual pro-environmental behaviors. Therefore, when individuals hold low values for preservation and appreciation of nature, they require strong collective efficacy levels in order to recycle and save energy.

Accordingly, with high utilization values, individuals also need substantial collective efficacy levels, with the power to counteract the negative effect of utilization values on recycling. These results indicate the relevance of promoting perceptions of collective efficacy for ecological behavior in individuals and groups, especially when they hold low levels of preservation and appreciation of nature, as well as strong utilization values. Putting the focus on cooperation and critical and eco-pedagogy (Kopnina, 2020) could be an advantage to encourage pro-environmental behavior in individuals, by increasing the confidence in the group capability to behave in a pro-environmental way. Nevertheless, no interactive effect or relationship was found between utilization and energy saving, perhaps owing to the moderating or mediating role of additional variables that were not studied in this study, necessitating further research on this link.

\section{Appendix 1}

See Table 5 
Table 5 Ad Hoc Scales

Collective Efficacy for Ecological Behavior Scale (CEfEB scale) and Individual Recycling Behavior Scale (IRB scale)

\section{Collective efficacy for Ecological Behavior Scale (CEfEB scale)}

To what extent do you feel that your group is capable of...

Item 1

Item 2

Item 3

Item 4

Item 5

Item 6

Item 7

Item 8

Individual recycling behavior scale (IRB scale)

As for recycling...

Item 1

Item 2

Item 3

Individual energy-saving behavior scale (IE-SB scale)

As for saving water and energy...

Item 1

Item 2

Item 3

Item 4

Item 5

Item 6
Separating all the paper and cardboard generated and depositing it in the appropriate container?

Separating all the glass generated and depositing it in the appropriate container?

Separating all the plastic generated and depositing it in the appropriate container?

Separating all potentially recyclable waste generated and deposit it in the appropriate container?

Taking appropriate measures to save water (shower, washing machine, etc.)?

Using non-polluting or collective means of transport (bike, bus, etc.)?

Turning off lights and electrical appliances when not in use?

Consuming only what is necessary?

I throw used batteries in a specific container for batteries

I recycle used paper and cardboard

I throw used glass bottles in specific containers for glass recycling

I take short showers to limit the use of water

I turn off the tap while brushing my teeth

I turn on the washing machine and/or dishwasher only when they are full

when I must travel short distances or when I travel through the city, I walk, cycle, or use public transport instead of taking the car or motorcycle

I turn off the lights when there is enough natural light

I turn off electrical appliances when I'm not using them

Funding Open Access funding provided thanks to the CRUE-CSIC agreement with Springer Nature.

\section{Declarations}

Conflict of interest This research did not receive any specific grant from funding agencies in the public, commercial, or not-for-profit sectors.

Open Access This article is licensed under a Creative Commons Attribution 4.0 International License, which permits use, sharing, adaptation, distribution and reproduction in any medium or format, as long 
as you give appropriate credit to the original author(s) and the source, provide a link to the Creative Commons licence, and indicate if changes were made. The images or other third party material in this article are included in the article's Creative Commons licence, unless indicated otherwise in a credit line to the material. If material is not included in the article's Creative Commons licence and your intended use is not permitted by statutory regulation or exceeds the permitted use, you will need to obtain permission directly from the copyright holder. To view a copy of this licence, visit http://creativecommons.org/licenses/by/4.0/.

\section{References}

Bamberg, S., Rees, J., \& Seebauer, S. (2015). Collective climate action: Determinants of participation intention in community-based pro-environmental initiatives. Journal of Environmental Psychology, 43, 155-165. https://doi.org/10.1016/j.jenvp.2015.06.006

Bandura, A. (2000). Exercise of human agency through collective efficacy. Current directions in psychological science, 9(3), 75-78. https://doi.org/10.1111/1467-8721.00064

Bandura, A. (2006). Guide for constructing self-efficacy scales. In: F. Pajares \& T. C. Urdan (Eds.), Selfefficacy beliefs of adolescents (pp. 307-337). Information Age Publishing: Greenwich.

Bandura, A. (2010). Self-Efficacy. John Wiley \& Sons, Inc. https://doi.org/10.1002/9780470479216. corpsy0836

Berenguer, J., Corraliza, J. A., \& Martín, R. (2005). Rural-urban differences in environmental concern, attitudes, and actions. European Journal of Psychological Assessment, 21(2), 128-138. https://doi. org/10.1027/1015-5759.21.2.128

Binngießer, J., \& Randler, C. (2015). Association of the environmental attitudes "preservation" and "utilization" with pro-animal attitudes. International Journal of Environmental \& Science Education, 10, 477-492.

Boeve-de Pauw, J., \& Van Petegem, P. (2013a). The effect of eco-schools on children's environmental values and behaviour. Journal of Biological Education, 47(2), 96-103. https://doi.org/10.1080/00219266. 2013.764342

Boeve-de Pauw, J., \& Van Petegem, P. (2013b). A cross-cultural study of environmental values and their effect on the environmental behavior of children. Environment and Behavior, 45(5), 551-583. https:// doi.org/10.1177/0013916511429819

Bogner, F. (2018). Environmental values (2-MEV) and appreciation of nature. Sustainability, 10(2), 350. https://doi.org/10.3390/su10020350

Bogner, F., \& Wiseman, M. (2006). Adolescents' attitudes towards nature and environment: Quantifying the 2-MEV model. The Environmentalist, 26(4), 247-254. https://doi.org/10.1007/s10669-006-8660-9

Brandsma, J. S., \& Blasch, J. (2019). One for All? - The impact of different types of energy feedback and goal setting on individuals' motivation to conserve Energy. SSRN Electronic Journal. https://doi.org/ 10.2139/ssrn. 3311128

Burneo, D., Cansino, J. M., \& Yñiguez, R. (2020). Environmental and socioeconomic impacts of urban waste recycling as part of circular economy. The case of cuenca (Ecuador). Sustainability (switzerland), 12(8), 3406. https://doi.org/10.3390/SU12083406

Casey, P. J., \& Scott, K. (2006). Environmental concern and behaviour in an Australian sample within an ecocentric - anthropocentric framework. Australian Journal of Psychology, 58(2), 57-67. https://doi. org/10.1080/00049530600730419

Chen, M.-F. (2015). Self-efficacy or collective efficacy within the cognitive theory of stress model: Which more effectively explains people's self-reported proenvironmental behavior? Journal of Environmental Psychology, 42, 66-75. https://doi.org/10.1016/j.jenvp.2015.02.002

Clayton, S. (2007). Domesticated nature: Motivations for gardening and perceptions of environmental impact. Journal of Environmental Psychology, 27(3), 215-224. https://doi.org/10.1016/j.jenvp.2007. 06.001

Corraliza, J. A., \& Berenguer, J. (2000). Environmental values, beliefs, and actions. Environment and Behavior, 32(6), 832-848. https://doi.org/10.1177/00139160021972829

Corral-Verdugo, V., Lucas, M. Y., Tapia-Fonllem, C., \& Ortiz-Valdez, A. (2020). Situational factors driving climate change mitigation behaviors: The key role of pro-environmental family. Environment, Development and Sustainability, 22(8), 7269-7285. https://doi.org/10.1007/s10668-019-00496-0

Cuadrado, E., \& Tabernero, C. (2015). Affective balance, team prosocial efficacy and team trust: A multilevel analysis of prosocial behavior in small groups. PLOS ONE, 10(8), e0136874. https://doi.org/10. 1371/journal.pone.0136874 
Cui, J., \& Zhang, L. (2008). Metallurgical recovery of metals from electronic waste: A review. Journal of Hazardous Materials, 158(2-3), 228-256. https://doi.org/10.1016/j.jhazmat.2008.02.001

de Albuquerque, C., de Oliveira Vicentini, J., \& Penatti Pipitone, M. A. (2015). O júri simulado como prática para a educação ambiental crítica. Revista Brasileira De Estudos Pedagógicos, 96(242), 199-215.

de Groot, J. I. M., \& Steg, L. (2008). Value orientations to explain beliefs related to environmental significant behavior. Environment and Behavior, 40(3), 330-354. https://doi.org/10.1177/0013916506297831

de Groot, J. I. M., \& Steg, L. (2009). Mean or green: Which values can promote stable pro-environmental behavior? Conservation Letters, 2(2), 61-66. https://doi.org/10.1111/j.1755-263X.2009.00048.x

Dutcher, D. D., Finley, J. C., Luloff, A. E., \& Johnson, J. B. (2007). Connectivity with nature as a measure of environmental values. Environment and Behavior, 39(4), 474-493. https://doi.org/10.1177/00139 16506298794

Echegaray, F., \& Hansstein, F. V. (2017). Assessing the intention-behavior gap in electronic waste recycling: The case of Brazil. Journal of Cleaner Production, 142, 180-190. https://doi.org/10.1016/j.jclepro. 2016.05.064

Everard, M., Reed, M. S., \& Kenter, J. O. (2016). The ripple effect: Institutionalising pro-environmental values to shift societal norms and behaviours. Ecosystem Services, 21, 230-240. https://doi.org/10.1016/j. ecoser.2016.08.001

Ferguson, M. A., \& Branscombe, N. R. (2010). Collective guilt mediates the effect of beliefs about global warming on willingness to engage in mitigation behavior. Journal of Environmental Psychology, 30(2), 135-142. https://doi.org/10.1016/j.jenvp.2009.11.010

Fritsche, I., Barth, M., Jugert, P., Masson, T., \& Reese, G. (2018). A social identity model of pro-environmental action (SIMPEA). Psychological Review, 125(2), 245-269. https://doi.org/10.1037/rev0000090

Gálvez-Ruiz, P., Conde-Pascual, E., Estrella-Andrade, A., García-Fernández, J., Romero-Galisteo, R. P., VélezColón, L., \& Pitts, B. G. (2018). Testing factorial invariance of the questionnaire of evaluation of the quality perceived in sports services in Spanish, Ecuadorian and Colombian users. Current Psychology, 40, 1249. https://doi.org/10.1007/s12144-018-0053-y

Gifford, R., \& Nilsson, A. (2014). Personal and social factors that influence pro-environmental concern and behaviour: A review. International Journal of Psychology, 49, 141. https://doi.org/10.1002/ijop.12034

Gómez-Baggethun, E., de Groot, R., Lomas, P. L., \& Montes, C. (2010). The history of ecosystem services in economic theory and practice: From early notions to markets and payment schemes. Ecological Economics, 69(6), 1209-1218. https://doi.org/10.1016/j.ecolecon.2009.11.007

Hayes, A. F., \& Preacher, K. J. (2013). Conditional process modeling: Using structural equation modeling to examine contingent causal processes. In G. R. Hancock \& R. O. Mueller (Eds.), Quantitative methods in education and the behavioral sciences: Issues, research, and teaching. Structural equation modeling: A second course (pp. 219-266). Charlotte: IAP Information Age Publishing.

Jia, X., O’Connor, D., Hou, D., Jin, Y., Li, G., Zheng, C., Ok, Y. S., Tsang, D. C. W., \& Luo, J. (2019). Groundwater depletion and contamination: Spatial distribution of groundwater resources sustainability in China. Science of the Total Environment, 672, 551-562. https://doi.org/10.1016/j.scitotenv.2019.03.457

Jugert, P., Greenaway, K. H., Barth, M., Büchner, R., Eisentraut, S., \& Fritsche, I. (2016). Collective efficacy increases pro-environmental intentions through increasing self-efficacy. Journal of Environmental Psychology, 48, 12-23. https://doi.org/10.1016/j.jenvp.2016.08.003

Kaiser, F. G., Brügger, A., Hartig, T., Bogner, F. X., \& Gutscher, H. (2014). Appreciation of nature and appreciation of environmental protection: How stable are these attitudes and which comes first? Revue Européenne De Psychologie Appliquée/european Review of Applied Psychology, 64(6), 269-277. https://doi. org/10.1016/j.erap.2014.09.001

Kaiser, F. G., Hubner, G., \& Bogner, F. (2005). Contrasting the theory of planned behavior with the valuebelief-norm model in explaining conservation behavior. Journal of Applied Social Psychology, 35(10), 2150-2170. https://doi.org/10.1111/j.1559-1816.2005.tb02213.x

Kibbe, A., Bogner, F. X., \& Kaiser, F. G. (2014). Exploitative vs. appreciative use of nature-Two interpretations of utilization and their relevance for environmental education. Studies in Educational Evaluation, 41, 106-112. https://doi.org/10.1016/j.stueduc.2013.11.007

King, A. M., Burgess, S. C., Ijomah, W., \& McMahon, C. A. (2006). Reducing waste: Repair, recondition, remanufacture or recycle? Sustainable Development, 14(4), 257-267. https://doi.org/10.1002/sd.271

Kopnina, H. (2020). Education for the future? Critical evaluation of education for sustainable development goals. The Journal of Environmental Education, 51(4), 280-291. https://doi.org/10.1080/00958964.2019. 1710444

Liu, W., \& Chen, J. (2019). Modified two major environmental values scale for measuring Chinese children's environmental attitudes. Environmental Education Research, 26, 1-18. https://doi.org/10.1080/13504 622.2019.1697431 
Mancha, R. M., \& Yoder, C. Y. (2015). Cultural antecedents of green behavioral intent: An environmental theory of planned behavior. Journal of Environmental Psychology, 43, 145-154. https://doi.org/10.1016/j. jenvp.2015.06.005

McCauley, D. J. (2006). Selling out on nature. Nature, 443(7107), 27-28. https://doi.org/10.1038/443027a

Meisenberg, G., \& Williams, A. (2008). Are acquiescent and extreme response styles related to low intelligence and education? Personality and Individual Differences, 44(7), 1539-1550. https://doi.org/10. 1016/j.paid.2008.01.010

Milfont, T. L., \& Duckitt, J. (2004). The structure of environmental attitudes: A first- and second-order confirmatory factor analysis. Journal of Environmental Psychology, 24(3), 289-303. https://doi.org/10. 1016/j.jenvp.2004.09.001

Milfont, T. L., Duckitt, J., \& Wagner, C. (2010). A cross-cultural test of the value attitude behavior hierarchy. Journal of Applied Social Psychology, 40, 2791-2813. https://doi.org/10.1111/j.1559-1816.2010.00681.x

Nasrollahi, Z., Hashemi, M., Bameri, S., \& Mohamad Taghvaee, V. (2018). Environmental pollution, economic growth, population, industrialization, and technology in weak and strong sustainability: Using STIRPAT model. Environment, Development and Sustainability. https://doi.org/10.1007/s10668-018-0237-5

Nord, M., Luloff, A. E., \& Bridger, J. C. (1998). The association of forest recreation with environmentalism. Environment and Behavior, 30(2), 235-246. https://doi.org/10.1177/0013916598302006

Ollinaho, O. I. (2016). Environmental destruction as (objectively) uneventful and (subjectively) irrelevant. Environmental Sociology, 2(1), 53-63. https://doi.org/10.1080/23251042.2015.1114207

Peattie, K., \& Peattie, S. (2009). Social marketing: A pathway to consumption reduction? Journal of Business Research, 62(2), 260-268. https://doi.org/10.1016/j.jbusres.2008.01.033

Reicher, S. D., Spears, R., \& Hasslam, S. A. (2010). The social identity approach in social psychology. In M. S. Wetherell \& C. T. Mohanty (Eds.), The SAGE Handbook of Identities (pp. 45-62). Thousand Oaks: SAGE Publications Ltd. https://doi.org/10.4135/9781446200889.n3

Roczen, N., Kaiser, F. G., Bogner, F. X., \& Wilson, M. (2014). A competence model for environmental education. Environment and Behavior, 46(8), 972-992. https://doi.org/10.1177/0013916513492416

Rudel, T. K., Roberts, J. T., \& Carmin, J. (2011). Political economy of the environment. Annual Review of Sociology, 37(1), 221-238. https://doi.org/10.1146/annurev.soc.012809.102639

Scannell, L., \& Gifford, R. (2013). Personally relevant climate change. Environment and Behavior, 45(1), 60-85. https://doi.org/10.1177/0013916511421196

Schultz, P. W., Shriver, C., Tabanico, J. J., \& Khazian, A. M. (2004). Implicit connections with nature. Journal of Environmental Psychology, 24(1), 31-42. https://doi.org/10.1016/S0272-4944(03)00022-7

Schumm, M. F., \& Bogner, F. X. (2016). How environmental attitudes interact with cognitive learning in a science lesson module. Education Research International, 2016, 1-7. https://doi.org/10.1155/2016/6136527

Shove, E. (2010). Beyond the ABC: Climate change policy and theories of social change. Environment and Planning A: Economy and Space, 42(6), 1273-1285. https://doi.org/10.1068/a42282

Stevenson, R. B., Wals, A. E. J., Heimlich, J. E., \& Field, E. (2017). Critical environmental education. In A. Russ \& M. E. Krasny (Eds.), Urban Environmental Education (pp. 51-58). Cornell: Cornell University Press.

Tabernero, C., \& Hernández, B. (2011a). Collective motivation for managing our common environment. In M. Bonaiuto, M. Bonnes, A. M. Nenci, \& G. Garrus (Eds.), Urban diversities-Environmental and social issues (pp. 193-202). Göttingen: Hogrefe Publishing.

Tabernero, C., \& Hernández, B. (2011b). Self-efficacy and intrinsic motivation guiding environmental behavior. Environment and Behavior, 43(5), 658-675. https://doi.org/10.1177/0013916510379759

Tabernero, C., Hernández, B., Cuadrado, E., Luque, B., \& Pereira, C. R. (2015). A multilevel perspective to explain recycling behaviour in communities. Journal of Environmental Management, 159, 192-201. https://doi.org/10.1016/j.jenvman.2015.05.024

Tacconi, L. (2012). Redefining payments for environmental services. Ecological Economics, 73, 29-36. https://doi.org/10.1016/j.ecolecon.2011.09.028

Tadaki, M., Sinner, J., \& Chan, K. M. A. (2017). Making sense of environmental values: a typology of concepts. Ecology and Society, 22(1), 7. https://doi.org/10.5751/ES-08999-220107

Tasa, K., Sears, G. J., \& Schat, A. C. H. (2011). Personality and teamwork behavior in context: The cross-level moderating role of collective efficacy. Journal of Organizational Behavior, 32(1), 65-85. https://doi.org/ 10.1002/job.680

Taylor, B., Chapron, G., Kopnina, H., Orlikowska, E., Gray, J., \& Piccolo, J. J. (2020). The need for ecocentrism in biodiversity conservation. Conservation Biology, 34(5), 1089-1096. https://doi.org/10.1111/ cobi. 13541

United Nations Environment Programme. (2011). Towards a Green Economy: Pathways to Sustainable Development and Poverty Eradication. https://sustainabledevelopment.un.org/index.php?page=view\&type= $400 \& \mathrm{nr}=126 \& \mathrm{menu}=35$ 
Wiseman, M., \& Bogner, F. (2003). A higher-order model of ecological values and its relationship to personality. Personality and Individual Differences, 34(5), 783-794. https://doi.org/10.1016/S0191-8869(02) 00071-5

Zeng, X., Song, Q., Li, J., Yuan, W., Duan, H., \& Liu, L. (2015). Solving e-waste problem using an integrated mobile recycling plant. Journal of Cleaner Production, 90, 55-59. https://doi.org/10.1016/j.jclepro.2014. 10.026

Zhou, K., \& Yang, S. (2016). Understanding household energy consumption behavior: The contribution of energy big data analytics. Renewable and Sustainable Energy Reviews, 56, 810-819. https://doi.org/10. 1016/j.rser.2015.12.001

Publisher's Note Springer Nature remains neutral with regard to jurisdictional claims in published maps and institutional affiliations. 